\title{
Finding the Betrayer Judas: Developing the Scale of the Typology of Follower's Intention
}

\author{
Kihwan Kim¹, Byeonghwa Park², Justin Antonio³, Janell Laws ${ }^{4}$, Victoria Vitale ${ }^{5}$
}

School of Management and Marketing, Kean University

\begin{abstract}
In the leadership theory study, there have been few studies to explore why and how followers develop a commitment to their leader. The current study attempts to develop an integrative model that describes the motives and process that followers foster loyalty to the leader. In the organization, members may have different motives to follow the leader. The current study discusses the motives to follow the leader from social exchange theory, economic exchange theory, social identity, and legitimacy theory. Also, different intentions will determine the quality of a follower's commitment to the leader. The current study suggests four levels or types of leader-follower relationships using two dimensions, physical and psychological distance. This study discusses how the quality of the leader-member relationship can be changed with the efforts of leader, follower, and both. Finally, the current study discusses future research issues, implications for practitioners, and limitations.
\end{abstract}

Keywords: Follower Intention; Typology; Psychological Distance; Physical Distance: Leadership Effectiveness 